Research Article

\title{
Study on Temporal and Spatial Characteristics of Overlying Strata in the Deep Coal Mining Process
}

\author{
Bang'an Zhang $\mathbb{D}^{1},{ }^{1}$ Yushun Yang $\mathbb{D}^{2,3}$ and Dongming Zhang $\mathbb{D}^{1}$ \\ ${ }^{1}$ School of Resources and Safety Engineering, Chongqing University, Chongqing 400044, China \\ ${ }^{2}$ Faculty of Architecture and Civil Engineering, Huaiyin Institute of Technology, Huaian 223003, China \\ ${ }^{3}$ State and Local Joint Engineering Laboratory for Gas Drainage \& Ground Control of Deep Mines, Henan Polytechnic University, \\ Jiaozuo 454003, China \\ Correspondence should be addressed to Yushun Yang; cqyysh@126.com
}

Received 20 May 2021; Accepted 18 August 2021; Published 6 October 2021

Academic Editor: shun liang

Copyright $\odot 2021$ Bang'an Zhang et al. This is an open access article distributed under the Creative Commons Attribution License, which permits unrestricted use, distribution, and reproduction in any medium, provided the original work is properly cited.

\begin{abstract}
This study adopts the stress relief method to test the in situ stress in the field to obtain the in situ stress distribution characteristics of no. $2+3 \#$ coal seam. A three-dimensional model was established with the no. S3012 working face as the engineering background, and the measured in situ stress values were applied to the three-dimensional model, and the spatial-temporal evolution characteristics of coal and rock mass around the stope during coal seam mining were studied. The specific conclusions are as follows: the three-dimensional stress distribution map in front of, behind, and on both sides of the working face in the process of coal mining are obtained. As the working face goes on, the maximum value of the supporting stress formed in front of, behind, and on both sides of the working face shifts to the corner, presenting a "hump-like" distribution. The stress concentration coefficient of front, back, and both sides of stope increases linearly with the increase of the mining size. Under the same mining size, the stress concentration coefficient in front of stope is the smallest, and the stress concentration coefficient on both sides is the largest. The three-dimensional displacement field distribution nephogram of overlying strata in the process of coal mining is obtained. With the continuous advance of the working face, the roof strata of coal seam undergo the continuous dynamic subsidence process, and the roof subsidence increases continuously, showing the shape of "bowl" with sharp bottom. In the process of working face mining, the roof displacement of coal seam showed an "O" shape evolution characteristic. The threedimensional distribution cloud map of the plastic zone of coal and rock mass in the process of the working face mining was obtained, and the failure volume of the plastic zone gradually increases with the continuous progress of the working face.
\end{abstract}

\section{Introduction}

China is one of the countries with the worst disasters in the world, especially the dynamic disasters generated in the process of coal resource mining, such as coal and gas outburst, rock burst, gas, and other disasters [1], which not only cause huge losses to people's lives and property but also seriously hinder the society, environment, and safe and efficient mining of coal resources. The occurrence of these disasters is closely related to the stress environment of the coal and rock mass. It is of great significance for the prevention and control of dynamic disasters such as coal and gas outburst to make clear the distribution characteristics of the stress field of the coal and rock mass and the evolution characteristics of the stress field of the surrounding rock mass during the mining process $[2,3]$.

The in situ stress field refers to the undisturbed natural stress field, also known as the original stress field, which consists of the tectonic stress field and the self-weight stress field of coal and rock mass. The tectonic stress field is formed by geological tectonic movement, which is complex and variable with uneven stress distribution. The horizontal stress in the shallow part of the crust is generally larger than the selfweight stress, which is about 1.5-2.0 times of the self-weight stress [4], while the horizontal stress is generated by the structural stress [5]. There are many in situ stress testing methods, among which the commonly used ones are stress (strain) relief and hydraulic fracturing [6]. In 1966, Li Siguang 
established China's first in situ stress observation station in Yaoxian, Hebei Province, and then, in situ stress testing developed rapidly [7, 8]. Zhang et al. [9] put forward the Kaiser effect method for the in situ stress test, and the test results are consistent with those of the in situ hollow inclusion stress relief method. In addition, the in situ stress test is carried out by using the stress relief method, and the rockburst tendency of the Micangshan tunnel is analyzed [10]. However, for the measurement of in situ stress under the condition of soft surrounding rock in deep coal mines, neither the hydraulic fracturing method nor the stress relief method can obtain the effective in situ stress value. Based on the mechanical characteristics of strong rheology of soft rock under the action of high ground stress [11], it is considered that the rock mass stress sensor can be embedded in the deep soft rock after drilling. With the rheology of the surrounding rock, the stress around the drilling hole gradually recovers to a certain value. The ground stress or disturbed stress state of the surrounding rock can be obtained through the monitoring of the perceived stress change of the rock mass stress sensor and the related inversion calculation; according to this, the rheological stress recovery method is proposed to test the in situ stress [12-14].

The appearance of underground stope pressure is closely related to the fracture structure of the overlying strata; the structural form and stability of the overlying strata directly impact on the occurrence characteristics of mine pressure. At present, domestic and foreign scholars have conducted a lot of research on the law of strata pressure in the working face and achieved rich results. In view of the impact characteristics of overburden structure movement on the strata pressure, microseismic positioning monitoring technology [6, 15], EH-4 detection technology [16], and other methods are used to carry out relevant research on the spatial structure form and disaster causing the mechanism of overlying rock. Jia et al. [17] analyzed the opening and closing process and form of "open close" fracture in depth according to the main factors of sand break and water break when the longitudinal fracture of overlying strata in the shallow buried and thin bedrock coal face is connected. According to the field measurement of mine pressure, it is considered that the periodic weighting step increases with the increase of bedrock thickness, and the weighting strength decreases with the increase of bedrock thickness [18]. It is revealed that the collapse and initial mining of the working face are the mechanisms of the problem of pressure support [19]. Wang and Ju [20] used the method of field observation and theoretical analysis to analyze the law of mine pressure appearance and its occurrence mechanism in the overlong fully mechanized mining face. The indoor similar simulation test method can effectively study the fracture characteristics of overburden in shallow and large mining height [21, 22], Liu et al. [13] analyzed the stress evolution process of the surrounding rock in the pressure relief area when mining in the short distance coal seam and believed that the stress in the floor rock in the working face decreased linearly. Computer simulation is also one of the commonly used means, and the commonly used numerical simulation software includes RFPA [23], $\operatorname{FLAC}^{3 \mathrm{D}}[24,25]$, and 3DEC/UDEC [26]. Zhang et al. [27] used the method of numerical simulation, similar simulation, and onsite monitoring to study the law of mine pressure appearance of repeated mining in very close seam.

To sum up, although scholars at home and abroad have carried out a series of research studies on the evolution characteristics of stress field of coal and rock mass, most of them are related research studies in the plane state, and most of the models are based on displacement constraints or similar simulation and numerical simulation tests under hydrostatic pressure. There are few reports on the study of stress field, displacement field, and plastic zone evolution characteristics of coal and rock mass in the three-dimensional state, especially the study of applying the measured in situ stress value on the boundary of the three-dimensional model. In the no. $2+3 \#$ coal seam of Shanmushu Coal Mine, there are many times of gas overrun in the roadways during driving, among which, there was one coal and gas outburst accident in the no. S3012-2 roadways during driving, the no. $2+3 \#$ coal seam is a typical coal and gas outburst coal seam, and the occurrence of coal and gas outburst and other disasters is closely related to the stress field environment. Therefore, this study used a combination of the onsite in situ stress test, three-dimensional similar simulation test, mining stress monitoring, and theoretical analysis to analyze in detail the evolution characteristics of the threedimensional mining stress field, displacement field, and plastic zone of coal and rock mass during the coal mining process. The research results have a guiding value for preventing the occurrence of disasters such as coal and gas outburst.

\section{Project Overview}

The no. $2+3 \#$ coal seam in no. S3012 working face of Shamushu Coal Mine belongs to coal and gas outburst coal seam. The gas overrun occurred many times in the process of driving and mining of each roadway, and one coal and gas outburst accident occurred during the driving of no. S3012-2 air roadway. The buried depth of no. $2+3 \#$ coal seam is $400-520 \mathrm{~m}$, the average thickness of coal seam is $3.1 \mathrm{~m}$, the average dip angle is $4^{\circ}$, the strike length of working face is $752 \mathrm{~m}$, and the inclined length is $138 \mathrm{~m}$. The working face layout is shown in Figure 1.

The direct roof of no. $2+3 \#$ coal seam is sandy mudstone with a thickness of about $3.0 \mathrm{~m}$, and the basic roof is sandstone carbonaceous mudstone with an average thickness of $6 \mathrm{~m}$. The direct bottom is clay rock, which is soft and expands with water, with an average thickness of $2.8 \mathrm{~m}$. The basic bottom is sandy mudstone with sandstone, with an average thickness of more than $5 \mathrm{~m}$. During the mining period, the working face is affected by some faults, resulting in roof fracture and coal seam missing, which causes adverse factors to the working face and has a great impact on the coal quality. The lithology of strata near no. $2+3 \#$ coal seam is given in Table 1, and the physical and mechanical parameters of each rock stratum are from the literature [28].

\section{In Situ Stress Test}

In the measurement of in situ stress in coal mine, it is more appropriate to apply the stress relief method in the stage of mine construction and production. Core drilling holes are 


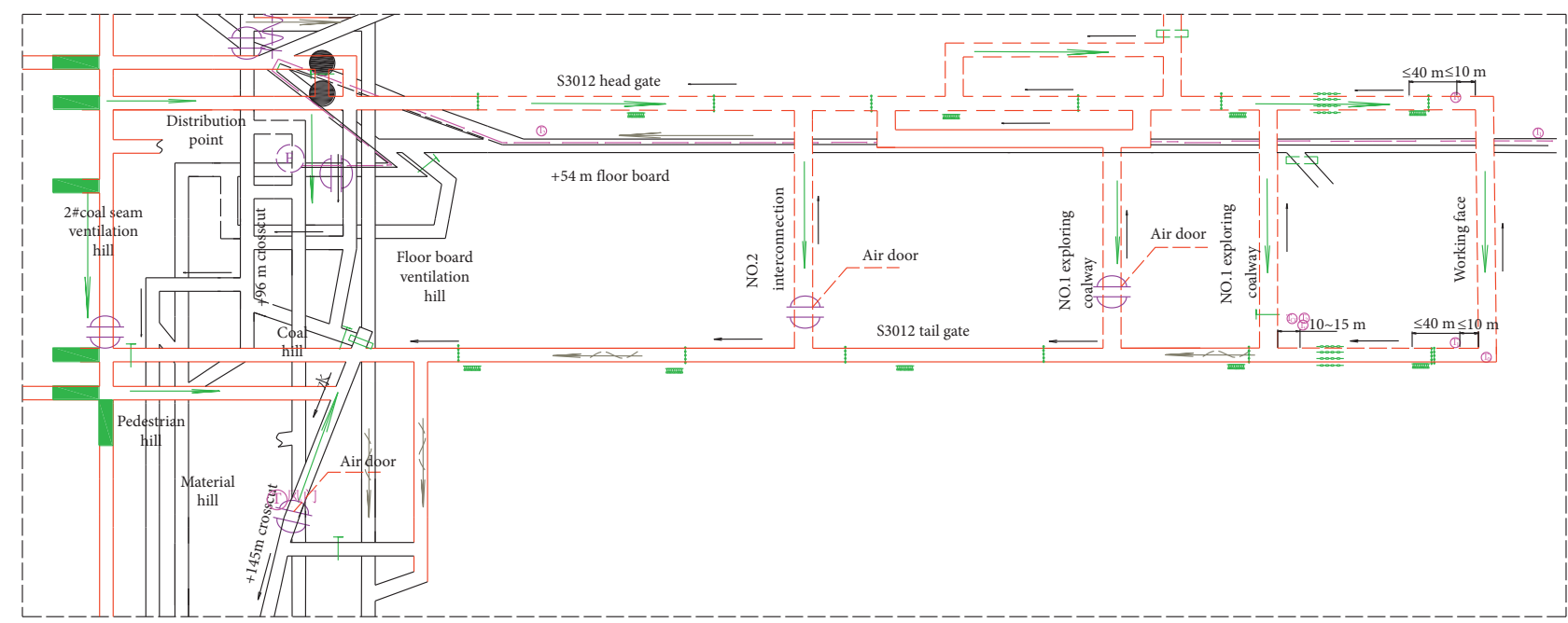

FIGURE 1: S3012 working face layout.

TABLE 1: Lithology of the adjacent strata of no. $2+3 \#$ coal seam.

\begin{tabular}{lcc}
\hline $\begin{array}{l}\text { Layer } \\
\text { number }\end{array}$ & Main lithology & Thickness $(\mathrm{m})$ \\
\hline 1 & Siltstone & 12.83 \\
2 & Fine sandstone & 5 \\
3 & Siltstone & 15 \\
4 & Siltstone-fine sandstone- & 15 \\
5 & mudstone & 15 \\
6 & Mudstone-fine sandstone & 44.3 \\
7 & Siltstone-fine sandstone & 30 \\
8 & Mudstone-siltstone & 0.7 \\
9 & K9 limestone & 0.65 \\
10 & No. 1\# coal seam & 8.5 \\
11 & Sandstone-claystone & 0.42 \\
12 & C2 coal seam & 10 \\
13 & Mudstone & 0.5 \\
14 & K8 argillaceous limestone & 6 \\
15 & Sandstone-carbonaceous & 3 \\
16 & mudstone & 3.1 \\
17 & Mudstone-argillaceous limestone & 2.8 \\
18 & No. 2+3\# coal seam & 6.3 \\
19 & Claystone & 2.9 \\
20 & Sandy mudstone & 9.3 \\
21 & Graystone & 2.4 \\
22 & Sandy mudstone & 6.3 \\
\hline
\end{tabular}

arranged in the rock mass to separate a section of core from the surrounding rock under three-dimensional stress. The data relationship curve of "strain-relief distance" in the process of core separation is tracked and recorded by installing a hollow core inclusion stress meter, so as to realize the purpose of in situ stress measurement. KX-81 hollow inclusion stress gauge is selected for this test, and the test site is selected in the surrounding rock layer of no. $2+3 \#$ coal seam, and the buried depth is about $450 \mathrm{~m}$. The depth of the construction large hole is $10.55 \mathrm{~m}$, and the installation angle is $36.5^{\circ}$, the drilling angle is $5^{\circ}$, and the azimuth angle is $325^{\circ}$ during installation. The site construction, installation, and test process are shown in Figure 2.
KJ327-F mine intrinsic safety digital strain gauge is used, and the accuracy is $0.1 \%$. The release process can be divided into three stages: in the first stage, before the core sleeve moves to the strain gauge position, the stress contact curve changes smoothly, and the variation range of each strain value is small. In the second stage, when the core sleeve is close to the position of strain gauge, the change range of strain value increases, and with the increase of release depth, the strain value gradually increases to the maximum value. In the third stage, after the strain reaches the peak value, the strain value fluctuates and tends to be stable with the increase of relief depth, and the stress relief process ends. The stress relief process curve is continuous and complete, and the data are valid, which can be used as the basis for stress calculation, as shown in Figure 3.

According to the test results in Figure 3, the in situ stress calculation program of hollow inclusion is used for iterative solution, and the in situ stress test results of the measuring point are obtained, as given in Table 2 .

\section{Three-Dimensional Strata Behavior Characteristics of Stope}

4.1. 3D Model Establishment. According to the engineering situation of S3012 working face, FLAC ${ }^{3 \mathrm{D}} 5.0$ [29] numerical simulation software is used to establish a three-dimensional model. The model size is $X \times Y \times Z=300 \mathrm{~m} \times 400 \mathrm{~m} \times 250 \mathrm{~m}$, $X$ direction is coal seam dip, $Y$ direction is coal seam strike, and $Z$ direction is vertical direction, as shown in Figure 4. If the coal seam is located about $204 \mathrm{~m}$ away from the top of the model and the buried depth of the coal seam is about $488 \mathrm{~m}$, the thickness of the overlying strata is about $284 \mathrm{~m}$, and the weight of the overlying strata is taken as $\gamma=25 \mathrm{kN} / \mathrm{m}^{2}$. Uniform load of 7.1 MPa was applied at the top of the model, displacement constraint was applied at the bottom of the model, and stress constraint was applied around the model. The maximum principal stress was $24.79 \mathrm{MPa}$ in $X$ direction and $14.55 \mathrm{MPa}$ in $Y$ direction. 


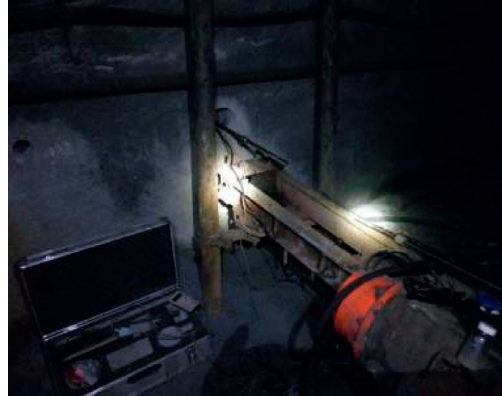

(a)

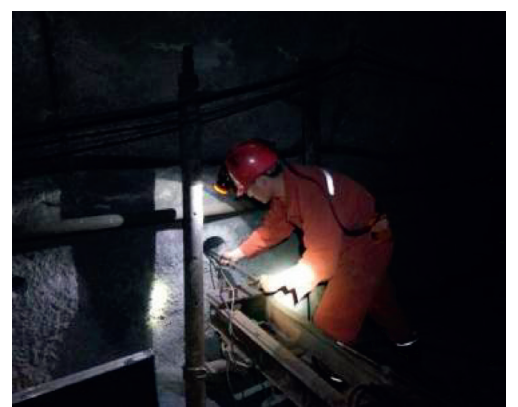

(b)

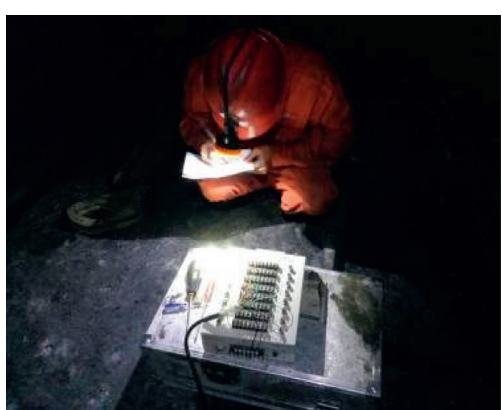

(c)

FIgURE 2: Filed test process. (a) Drilling construction. (b) Stress gauge installation. (c) Data collection.

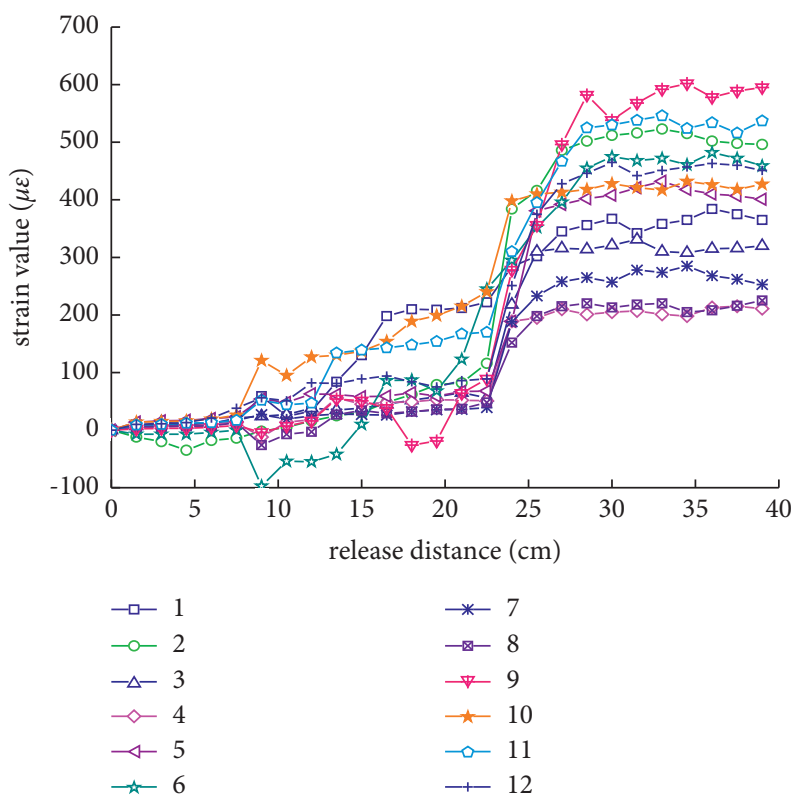

FIGURE 3: Stress relief curves during the drilling process.

TABLE 2: In situ stress test results.

\begin{tabular}{|c|c|c|c|c|c|}
\hline Principal stress & Measured value (MPa) & Azimuth angle $\left({ }^{\circ}\right)$ & Dip angle $\left({ }^{\circ}\right)$ & Vertical stress $\left(\sigma_{v} / \mathrm{MPa}\right)$ & $\sigma_{i} / \sigma_{v}$ \\
\hline$\overline{\sigma_{1}}$ & 24.79 & 144.45 & 3.91 & & 2.30 \\
\hline$\sigma_{2}$ & 14.55 & 52.64 & 24.86 & 10.8 & 1.35 \\
\hline$\sigma_{3}$ & 9.87 & 64.8 & 242.81 & & 0.91 \\
\hline
\end{tabular}

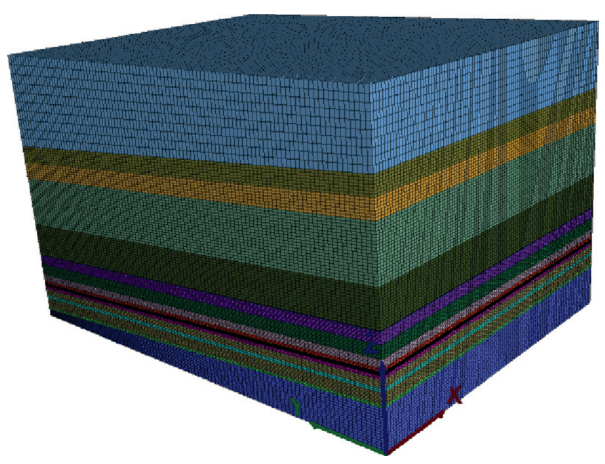

FIgURE 4: FLAC3D three-dimensional model. 
Assuming that the interior of each rock stratum is an isotropic continuous medium, all rock masses conform to the Mohr-Coulomb failure criterion. In this numerical simulation, a total of $240 \mathrm{~m}$ is mined, and each mining is $20 \mathrm{~m}$, which is completed in 12 times. The mining range is $84-216 \mathrm{~m}$ in $X$ direction and $110-350 \mathrm{~m}$ in $Y$ direction, with protective coal pillars left and right in front of and behind the working face. Figure 5 only shows that the mining dimensions of the working face are $20 \mathrm{~m}, 40 \mathrm{~m}, 600 \mathrm{~m}, 120 \mathrm{~m}$, $180 \mathrm{~m}$, and $240 \mathrm{~m}$.

4.2. Three-Dimensional Stress Field Analysis. In order to more intuitively show the stress evolution law in front, back, and both sides of the coal seam mining process, make a profile inside and parallel to the coal seam and import the results into Tecplot10.0 software for analysis. The stress evolution law in front, back, and both sides of the coal seam in the process of mining is shown in Figure 6.

It can be seen from Figure 6 that the coal and rock mass around the coal seam are in stress balance state before the working face is mined. Under the influence of mining, the stress field around the coal and rock mass redistributes, and the stress concentration phenomenon appears in front of and behind the working face and on both sides, and the stress relief area appears in the roof and floor strata of the working face. With the working face moving forward, the range of stress field gradually increases and moves forward gradually, thus forming mobile abutment stress. The height and width of the stress relief zone also increase with the increase of the excavation size. When the working face is mined for $20 \mathrm{~m}$, the maximum concentrated stress is 16.99 $\mathrm{MPa}$ at about $10 \mathrm{~m}$ in front of the working face, and the stress concentration coefficient is 1.4. The maximum concentrated stress is $17.28 \mathrm{MPa}$ and the stress concentration coefficient is 1.43 at about $10 \mathrm{~m}$ behind the working face. There is a stress concentration at $6 \mathrm{~m}$ on the left and right sides of the working face, the maximum value is $18.23 \mathrm{MPa}$, and the stress concentration coefficient is 1.51 . It can be seen that the value of the concentrated stress on both sides of the working face is greater than that on the back and greater than that on the front, and there are $84 \mathrm{~m}$ protective coal pillars on both sides of the working face, resulting in the same value of the maximum concentrated stress on both sides.

When the working face is $40 \mathrm{~m}$, the stress concentration area in front of the working face moves forward, and the maximum value of the concentration stress is $16.87 \mathrm{MPa}$ and the stress concentration coefficient is 1.39 at about $10 \mathrm{~m}$ in front of the working face. The maximum concentrated stress is $17.50 \mathrm{MPa}$ and the stress concentration coefficient is 1.45 at about $10 \mathrm{~m}$ behind the working face. The maximum concentrated stress is $20.03 \mathrm{MPa}$ and the stress concentration coefficient is 1.66 at $6 \mathrm{~m}$ on the left and right sides of the working face. It can be seen that the maximum value of the front and back concentrated stress of the working face after $20 \mathrm{~m}$ and $40 \mathrm{~m}$ of coal mining occurs about $10 \mathrm{~m}$ in the front and back of the goaf, and the maximum value of the two sides concentrated stress of the working face appears about
$6 \mathrm{~m}$ in the right and left of the goaf. When the working face is mined for $60 \mathrm{~m}$, the concentrated stress is $16.77 \mathrm{MPa}$ at about $10 \mathrm{~m}$ in front of the working face and $17.15 \mathrm{MPa}$ at about $10 \mathrm{~m}$ in back of the working face, but the stress concentration in front, back, and both sides of the working face is in the shape of "hump-like," that is to say, after the coal seam is mined to $60 \mathrm{~m}$, the maximum concentrated stress value appears at the corner of the goaf in front of the working face. At this time, the maximum concentrated stress value in front of the working face is $17.69 \mathrm{MPa}$, and the stress concentration coefficient is 1.46 . The maximum concentrated stress behind the working face is $18.16 \mathrm{MPa}$, and the stress concentration coefficient is 1.5. Similarly, the maximum value of concentrated stress is $20.78 \mathrm{MPa}$ and the coefficient of stress concentration is 1.72 at $6 \mathrm{~m}$ near the goaf on the left and right sides of the working face. With the continuous advance of the working face, the maximum value of the concentrated stress in front, rear, left, and right of the working face increases gradually. When the working face is pushed $240 \mathrm{~m}$, the maximum value of the concentrated stress in front of the working face reaches $20.84 \mathrm{MPa}$, and the stress concentration coefficient is 1.72 . The maximum concentrated stress at the back of the working face is $23.6 \mathrm{MPa}$, and the stress concentration coefficient is 1.95 . The maximum concentrated stress of the left and right sides of the working face is $24.73 \mathrm{MPa}$, and the stress concentration coefficient is 2.04 .

Based on the above analysis, it can be seen that when the working face is mined for $20 \mathrm{~m}$ and $40 \mathrm{~m}$, the maximum abutment stress formed in front and back of the working face occurs in front and behind the middle of the working face. The maximum abutment stress on both sides of the working face occurs on both sides of the middle of the working face. When the working face is recovered to $60 \mathrm{~m}$, the maximum value of the abutment stress formed at the back of the working face is shifted from the front and back of the middle of the working face to both sides, so that the maximum value of the supporting stress appears at the corner in front of the working face, and the abutment stress formed at both sides of the working face has the same variation law, showing a "hump-like" distribution. According to the above analysis, the change law of stress concentration coefficient in front, back, and both sides of the goaf is shown in Figure 7.

It can be seen from Figure 7 that with the continuous forward movement of the working face, the stress concentration coefficient of the front, back, and both sides of the goaf increases gradually, and under the same mining size, the stress concentration coefficient in front of the working face is the smallest, and the stress concentration coefficient of both sides of the working face is the largest. There is a linear relationship between the stress concentration factor and the mining size, as shown in the following equation.

$$
\gamma=a+b l .
$$

In the formula, $\gamma$ is the stress concentration factor, $l$ is the working face mining size (m), and $a$ and $b$ are the linear fitting coefficients.

The fitting parameters of linear regression are given in Table 3. 


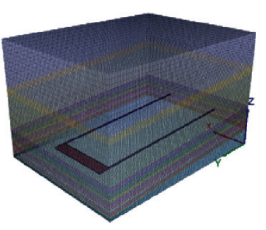

(a)

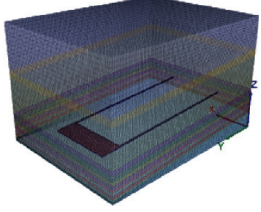

(b)

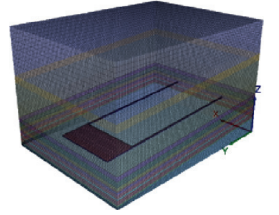

(c)

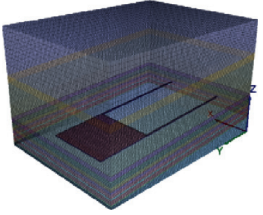

(d)

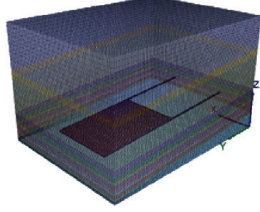

(e)

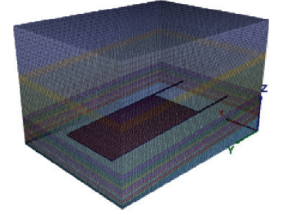

(f)

Figure 5: Working face mining dimension diagram. (a) $20 \mathrm{~m}$. (b) $40 \mathrm{~m}$. (c) $60 \mathrm{~m}$. (d) $120 \mathrm{~m}$. (e) $180 \mathrm{~m}$. (f) $240 \mathrm{~m}$.

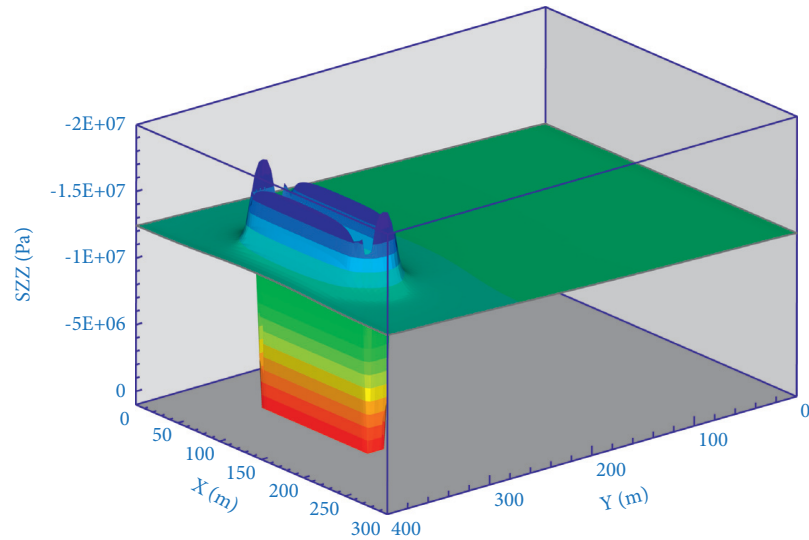

(a)

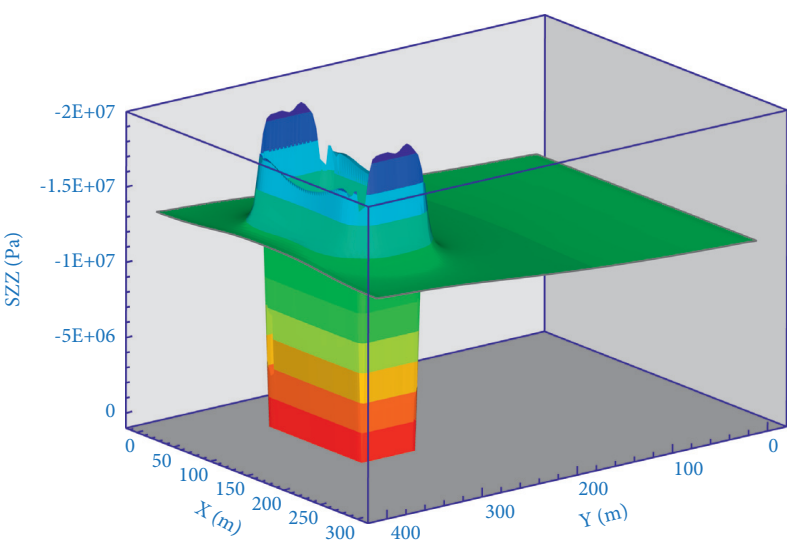

(c)

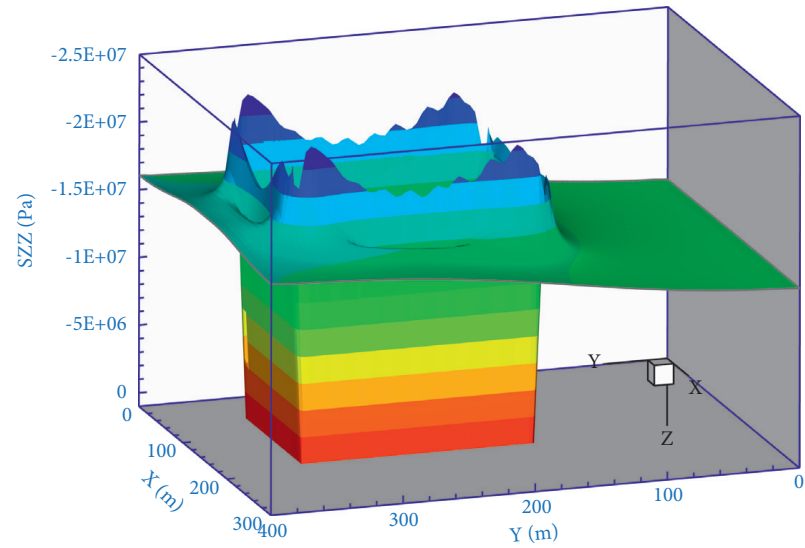

(e)

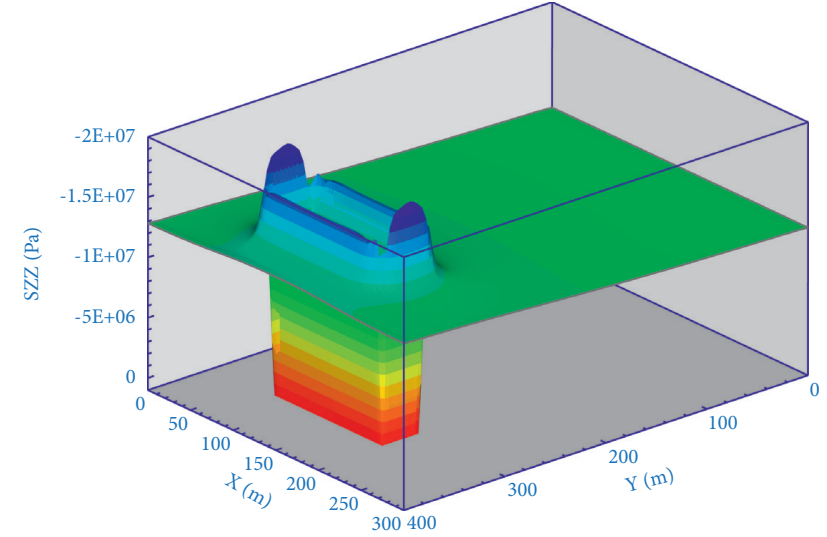

(b)

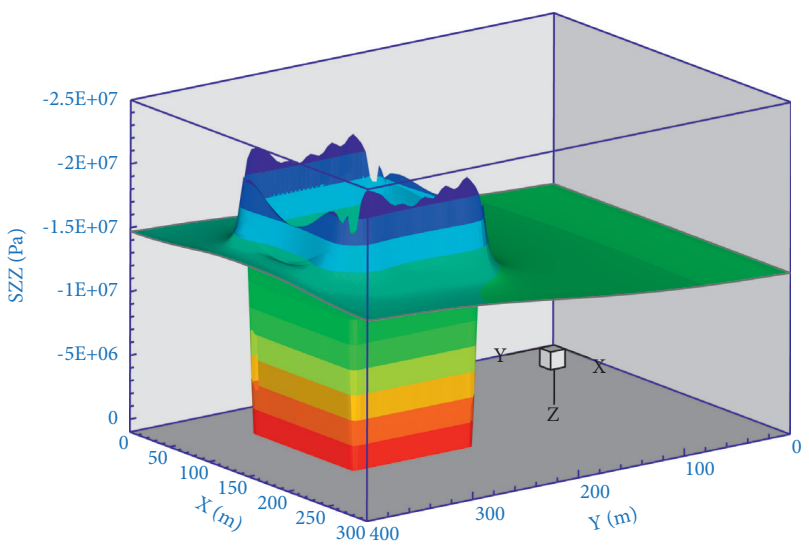

(d)

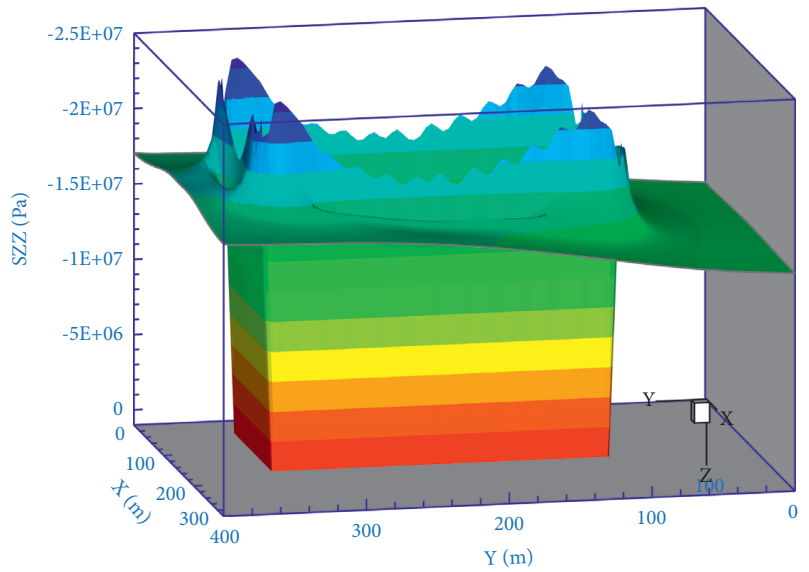

(f)

FiguRE 6: Stress evolution law in front, back, and both sides of the coal seam mining process. (a) $20 \mathrm{~m}$. (b) $40 \mathrm{~m}$. (c) $60 \mathrm{~m}$. (d) $120 \mathrm{~m}$. (e) $180 \mathrm{~m}$. (f) $240 \mathrm{~m}$. 


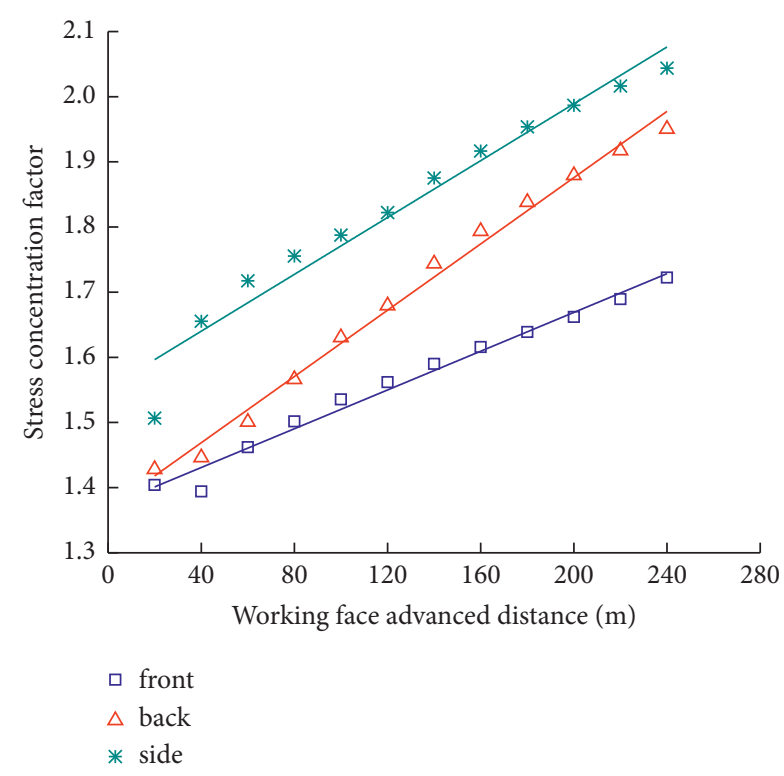

FIgURE 7: Variation law of the stress concentration factor in front, back, and both sides of goaf during the mining process.

TABLE 3: Fitting parameters of the coal-rock stress concentration factor and mining dimension around the working face.

\begin{tabular}{lccc}
\hline \multirow{2}{*}{ Stress concentration factor } & \multicolumn{2}{c}{ Fitting parameters } & $R^{2}$ \\
& $a$ & $b$ & \\
\hline Forward & 1.55287 & 0.01246 & 0.9562 \\
Near & 1.36718 & 0.00293 & 0.9922 \\
Both sides & 1.3714 & 0.00149 & 0.9830 \\
\hline
\end{tabular}

In order to more clearly show the stress variation law during the mining process of the working face, make a section along the $X$ direction of the three-dimensional model (that is, $X=150 \mathrm{~m}$ profile), make a section along the direction of the coal seam inside the coal seam, extract the intersection of the two sections, and draw the abutment stress evolution law in the mining process of the working face, as shown in Figure 8.

It can be seen from Figure 8 that after the coal seam mining, there is a stress concentration phenomenon in front and back of the working face, and the roof and floor strata at the working face are pressure relief areas. The larger the coal seam advances, the larger the pressure relief area. With the working face moving forward, the stress concentration coefficient in front and back of the working face is increasing, and the stress concentration coefficient behind the working face is slightly higher than the front stress concentration coefficient. It can be seen that with the continuous advancement of the working face, the coal wall and the goaf move forward continuously, resulting in the formation of movable abutment stress in front and back the working face and the formation of a stress reduction zone, a stress increasing zone, and an original stress zone in front of the working face.

4.3. Three-Dimensional Displacement Field Analysis. In order to visually show the migration law of overburden strata during coal seam mining, make a cutting plane along the coal seam in the roof rock layer $0.75 \mathrm{~m}$ away from the coal seam, extract the cutting plane displacement, and import the results into Tecplot 10.0 software for analysis. The migration law is shown in Figure 9.

It can be seen from Figure 9 that as the working face continues to move forward, the amount of coal roof subsidence gradually increases, and the roof rock layer is in the shape of a "bowl" with a sharp bottom. When the working face is stopped at $20 \mathrm{~m}$, the roof subsidence is $210.19 \mathrm{~mm}$; when the working face is recovered at $40 \mathrm{~m}$, the roof subsidence is $349.73 \mathrm{~mm}$; when the working face is recovered at $60 \mathrm{~m}$, the roof subsidence is $460.76 \mathrm{~mm}$; when the working face is recovered at $120 \mathrm{~m}$, the roof subsidence is $460.76 \mathrm{~mm}$; the sinking amount is $700.07 \mathrm{~mm}$; when the working face is mined at $180 \mathrm{~m}$, the roof sinking amount is $879.13 \mathrm{~mm}$; when the working face is mined at $240 \mathrm{~m}$, the roof sinking amount is $1060.20 \mathrm{~mm}$.

In order to more vividly represent the roof strata migration rule in the mining process of the working face, cut the three-dimensional model along the $X$ direction (i.e., $X=150 \mathrm{~m}$ section), cut the roof strata $0.75 \mathrm{~m}$ away from the coal seam along the coal seam direction, extract the intersection line of the two sections, and draw the roof strata migration law in the mining process of the working face, as shown in Figure 10.

In the mining process of the working face, the coal seam roof rock layer undergoes the continuous dynamic subsidence process, make the cutting plane at $Z=100 \mathrm{~m}$, and extract the displacement nephogram at $Z=100 \mathrm{~m}$ during the mining of the working face, as shown in Figure 11.

It can be seen from Figure 11 that in the process of mining, the displacement of the coal seam roof exhibits an "O" shape evolution law, that is, there is a displacement "O" shape circle. In the early stage of mining, the displacement of roof strata is approximately elliptical, the $X$ direction is the long axis of ellipse, and the $Y$ direction is the short axis of ellipse. With the development of the working face, that is, the ratio of long axis to short axis is decreasing, and the subsidence area of roof in goaf is expanding. When the ratio of long axis to short axis is close to 1 , the influence area of roof subsidence is approximately " $\mathrm{O}$ " shape. With the continuous development of the working face, the $X$ direction becomes elliptical short axis, the $Y$ direction becomes elliptical long axis, and the subsidence area of the roof in the goaf increases along the long axis.

4.4. Three-Dimensional Plastic Zone Analysis. In order to more vividly represent the destruction law of the roof and floor rock layers during working face mining, the distribution law of the plastic area of the coal and rock mass in the mining process of the working face is extracted by writing fish statement, as shown in Figure 12.

It can be seen from Figure 12 that after the coal seam is mined, there is a plastic area around the working face, and the area of the plastic zone gradually increases as the working face goes on. After the coal seam is excavated for $20 \mathrm{~m}$, the coal and rock mass around the working face have shear and tensile failure, among which the number of 


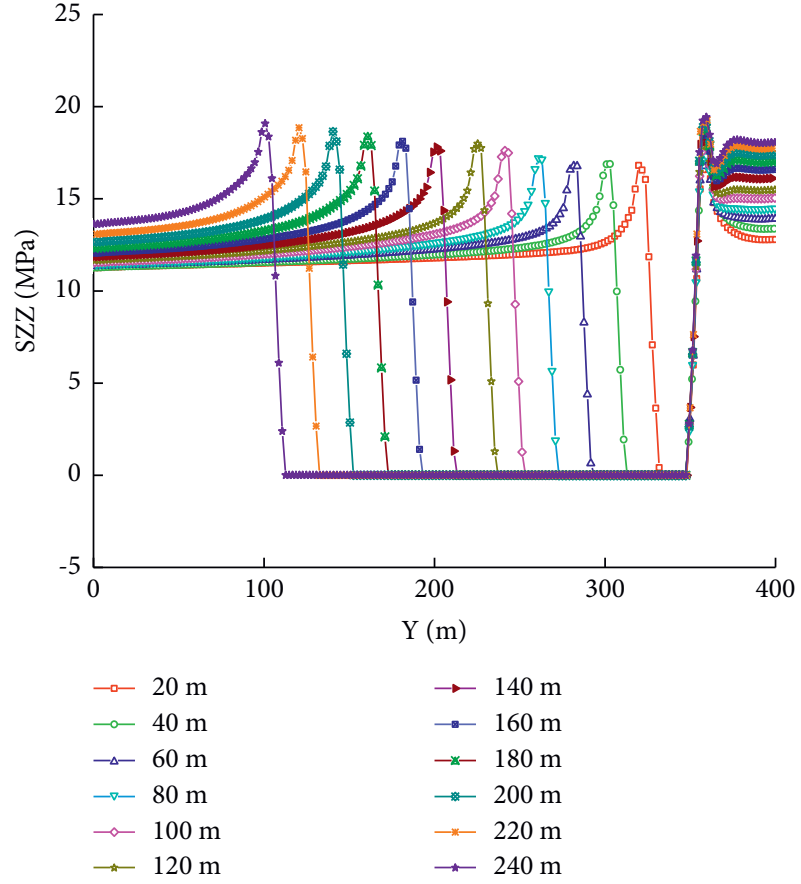

(a)

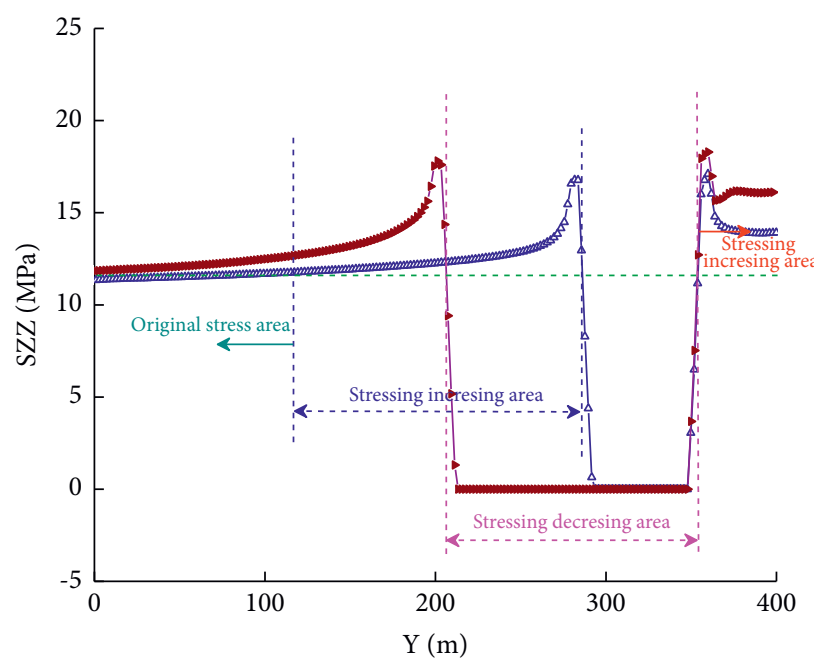

$\rightarrow 60 \mathrm{~m}$

Figure 8: Stress evolution law of $X=150 \mathrm{~m}$ section and intersection along the coal seam direction in the mining process.

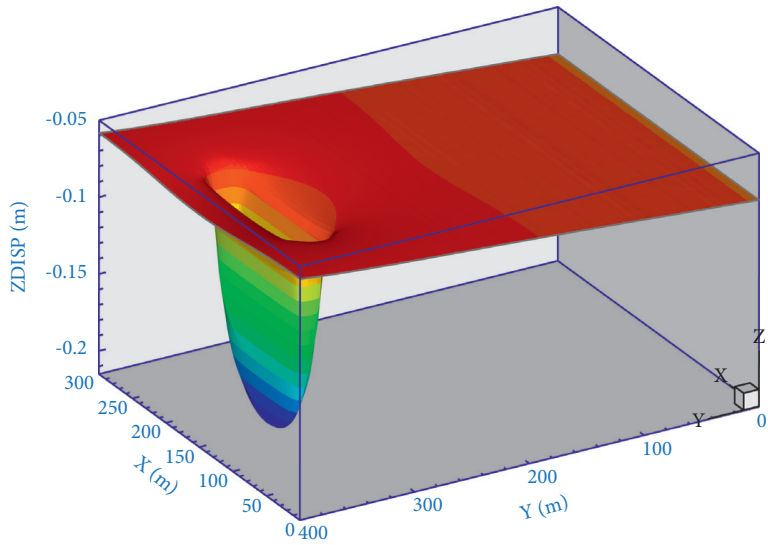

(a)

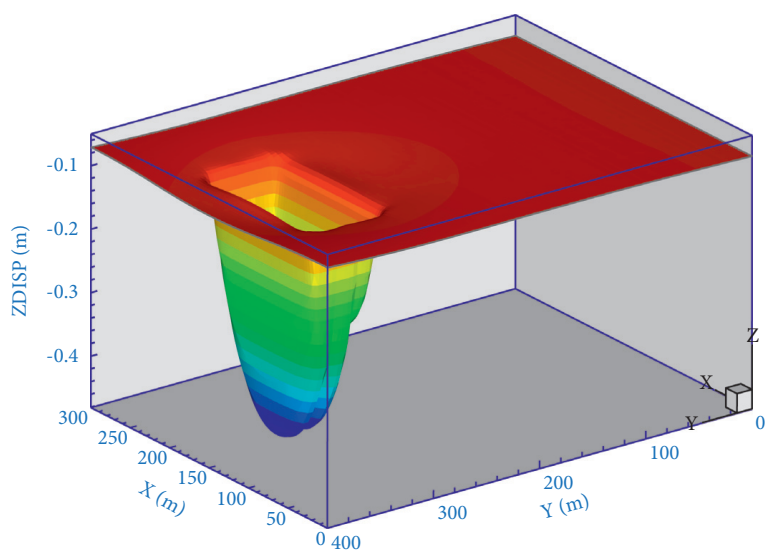

(c)

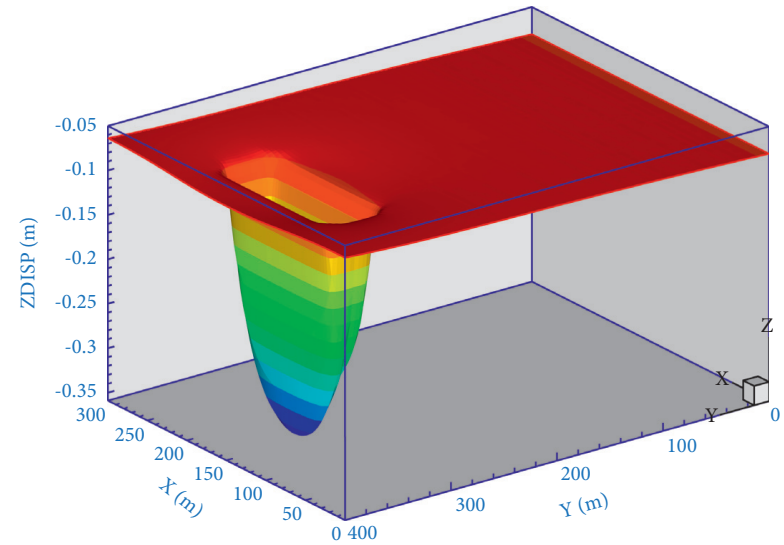

(b)

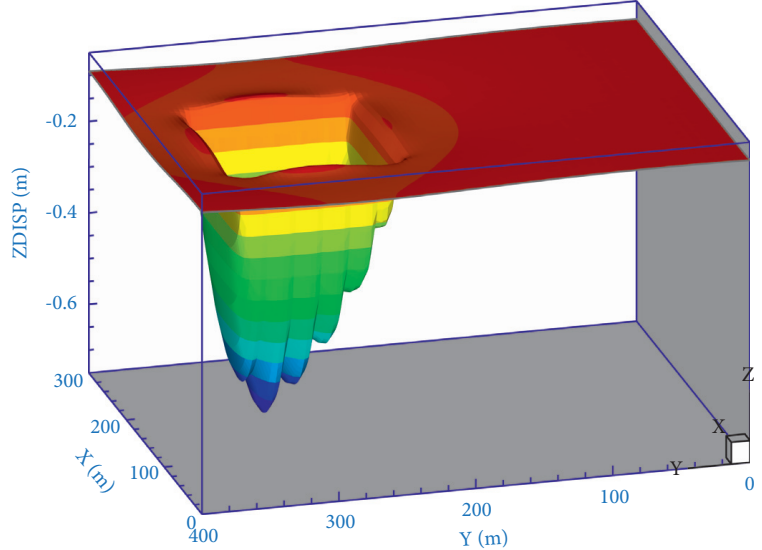

(d)

FIgURE 9: Continued. 


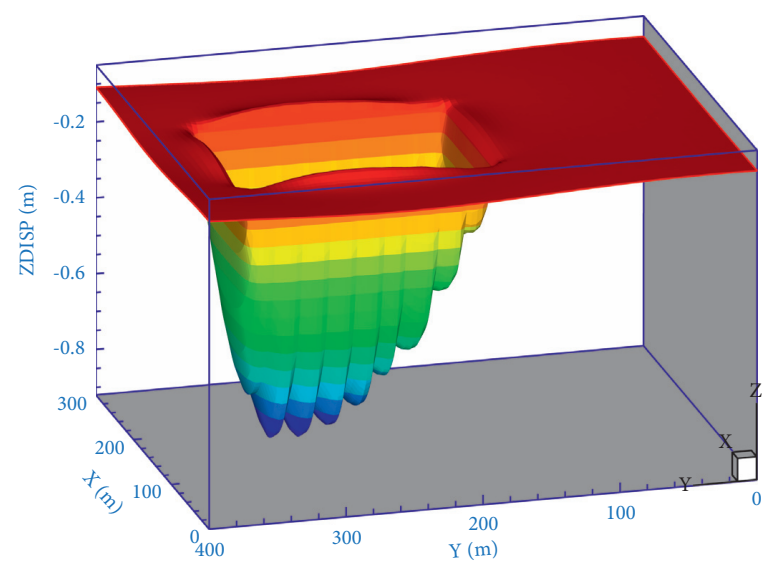

(e)

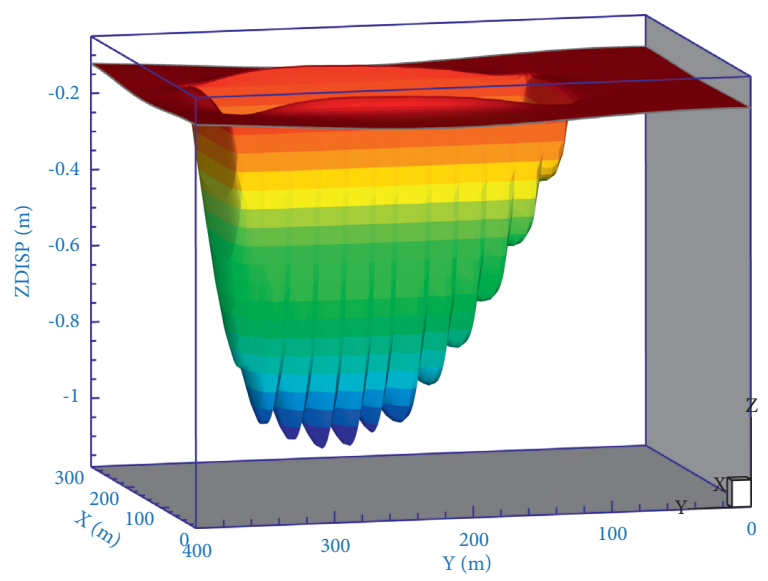

(f)

FIgURe 9: Movement law of coal seam roof rock stratum during the mining face. (a) $20 \mathrm{~m}$. (b) $40 \mathrm{~m}$. (c) $60 \mathrm{~m}$. (d) $120 \mathrm{~m}$. (e) $180 \mathrm{~m}$. (f) $240 \mathrm{~m}$.

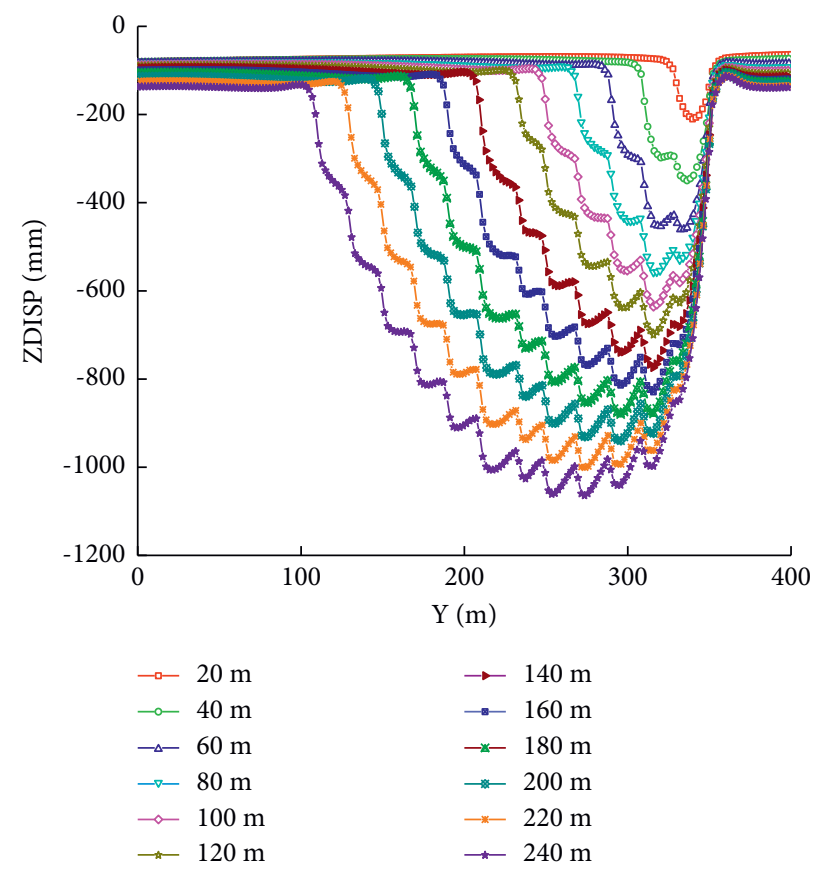

FIGURE 10: Variation curves of roof subsidence during coal seam mining.

shear_now failure of plastic yield units is 11481, the number of tensile_now failure is 0 , the number of shear_past failure is 115076 , and the number of tensile_past failure is 4835 . After the coal seam is excavated for $40 \mathrm{~m}$, the number of shear_now failure of plastic yielding units is 213229 , the number of tensile_now failure is 186 , the number of shear_past failure is 318839 , and the number of tensile_past failure is 13374. After the coal seam is excavated for $60 \mathrm{~m}$, the number of shear_now failure of plastic yielding units is 379657, the number of tensile_now failure is 147 , the number of shear_past failure is 599482, and the number of tensile_past failure is 25752. After the coal seam is excavated for $120 \mathrm{~m}$, the number of shear_now failure of plastic yielding units is
553339 , the number of tensile_now failure is 69 , the number of shear_past failure is 1480000 , and the number of tensile_past failure is 84830 . After the coal seam is excavated for $180 \mathrm{~m}$, the number of shear_now failure of plastic yielding units is 678039 , the number of tensile_now failure is 582, the number of shear_past failure is 2540000 , and the number of tensile_past failure is 208402 . After the coal seam is excavated for $240 \mathrm{~m}$, the number of shear_now failure of plastic yielding units is 840727 , the number of tensile_now failure is 2909 , the number of shear_past failure is 3700000 , and the number of tensile_past failure is 4915348 . In the mining process of the working face, the variation curves of the number of plastic zone units are shown in Figure 13. 


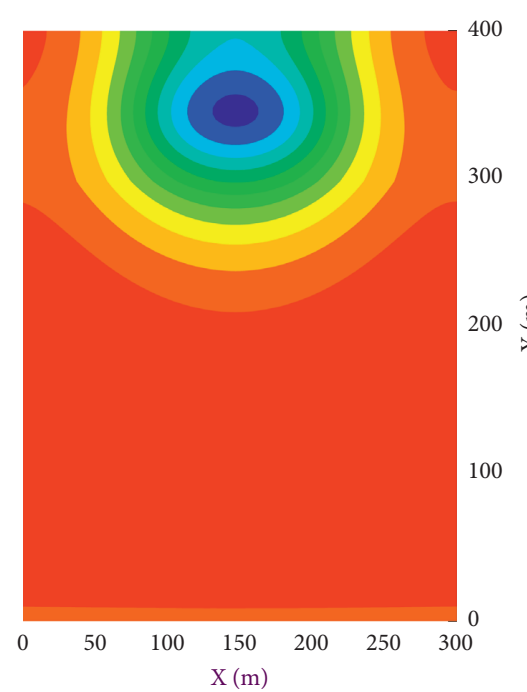

(a)

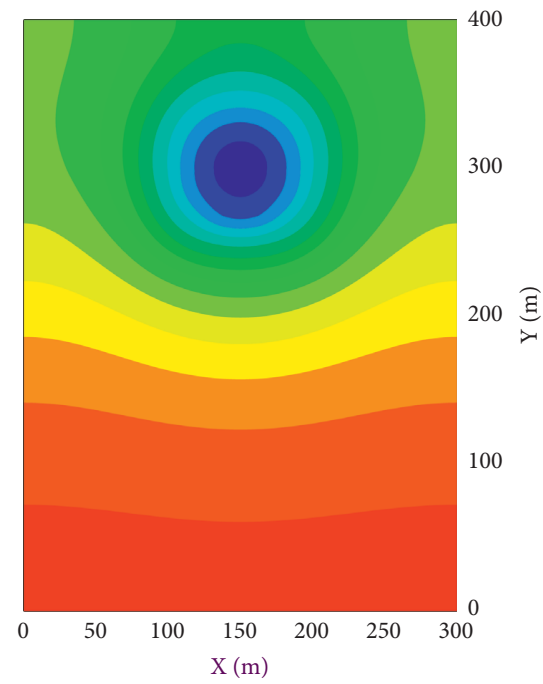

(d)

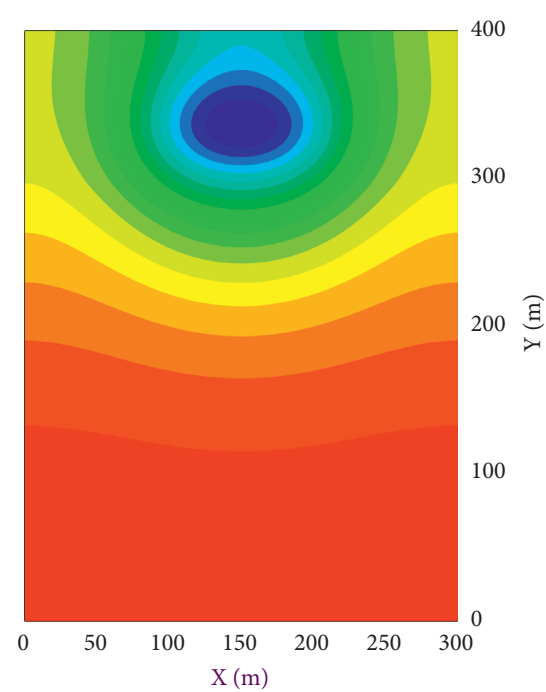

(b)

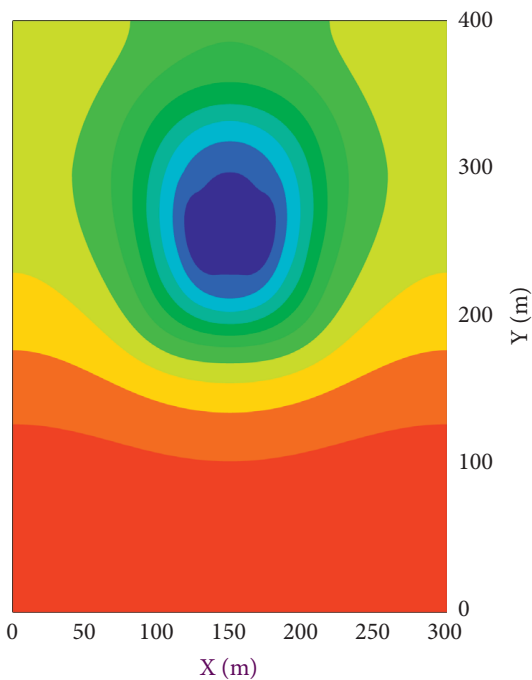

(e)

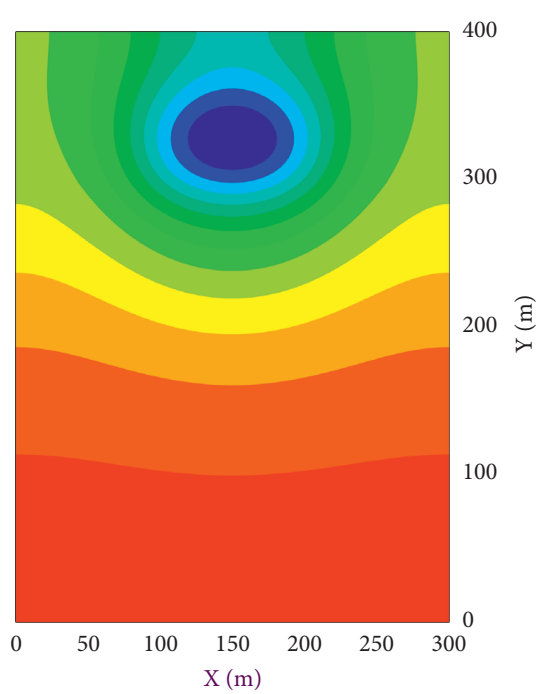

(c)

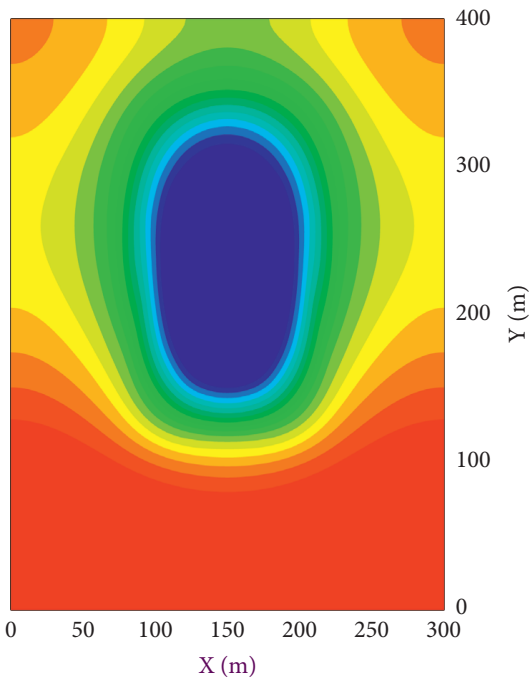

(f)

FiguRE 11: Displacement nephogram of roof strata in $Z=100 \mathrm{~m}$ section during coal seam mining. (a) $20 \mathrm{~m}$. (b) $40 \mathrm{~m}$. (c) $60 \mathrm{~m}$. (d) $120 \mathrm{~m}$. (e) $180 \mathrm{~m}$. (f) $240 \mathrm{~m}$.

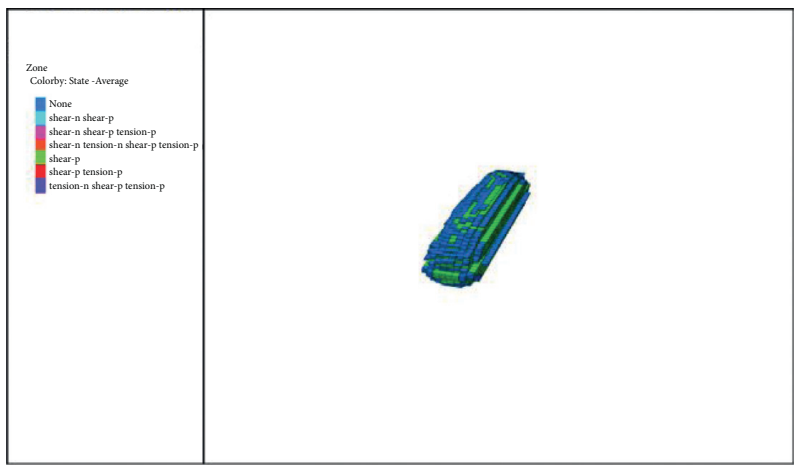

(a)

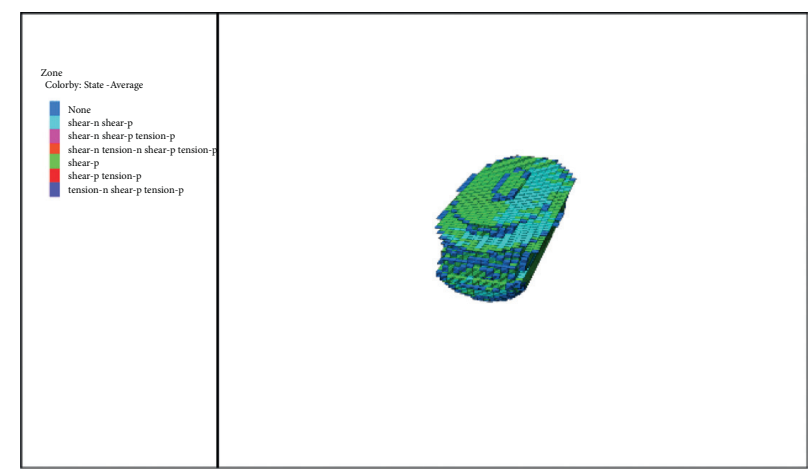

(b)

Figure 12: Continued. 


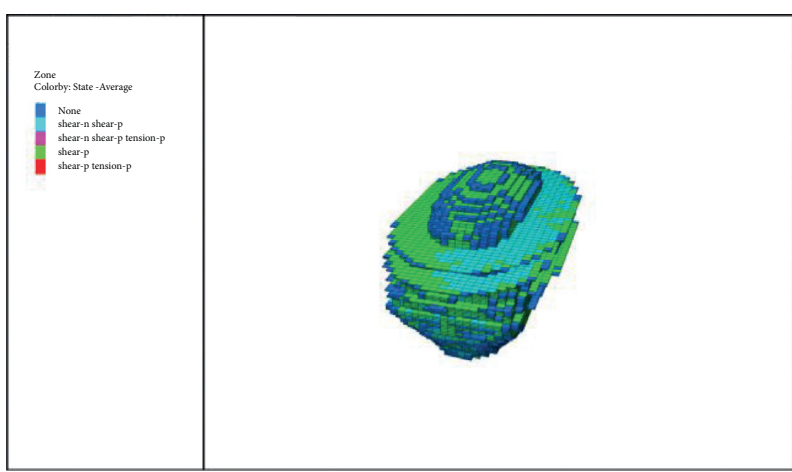

(c)

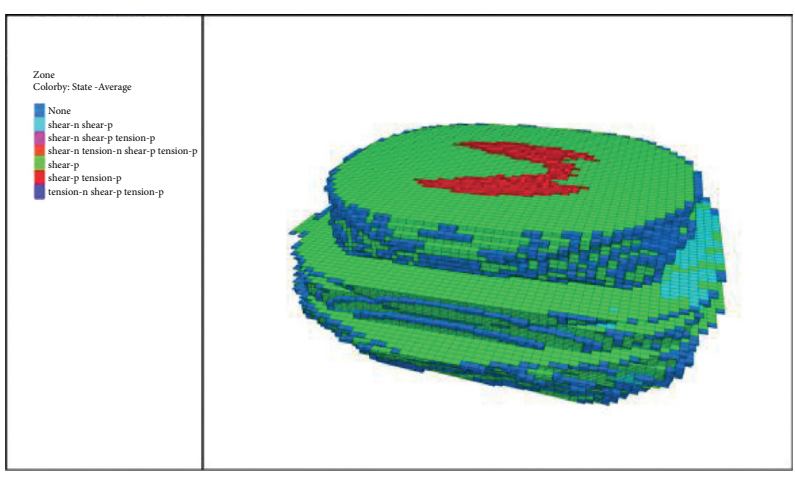

(e)

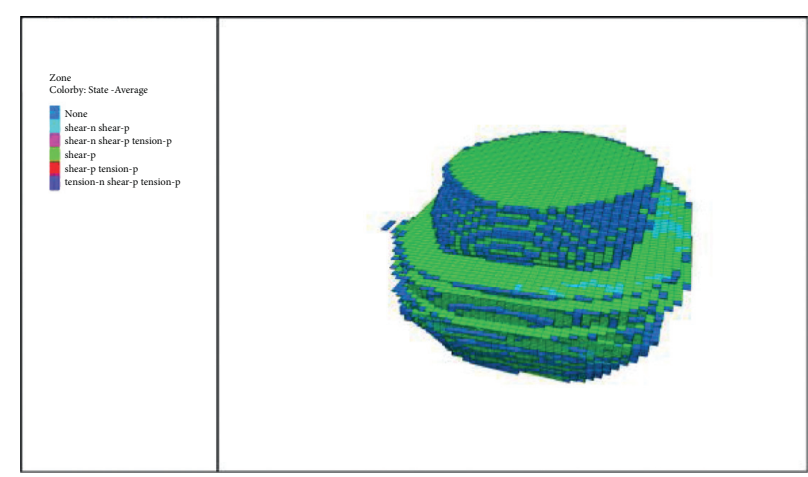

(d)

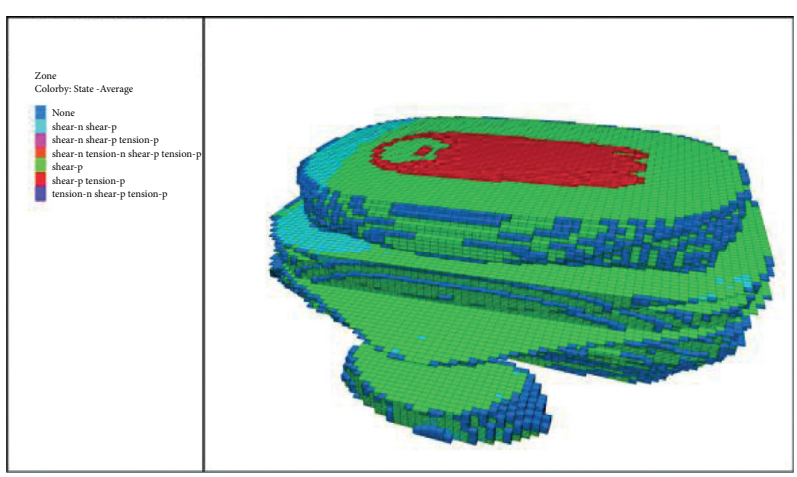

(f)

FIgURe 12: Distribution law of plastic zone in the mining process of working face. (a) $20 \mathrm{~m}$. (b) $40 \mathrm{~m}$. (c) $60 \mathrm{~m}$. (d) $120 \mathrm{~m}$. (e) $180 \mathrm{~m}$. (f) $240 \mathrm{~m}$.

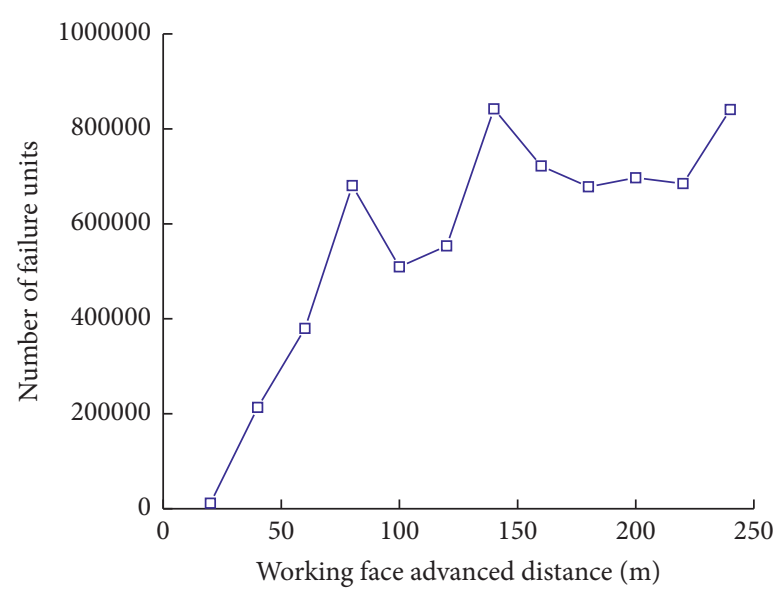

$\rightarrow$ shear_now

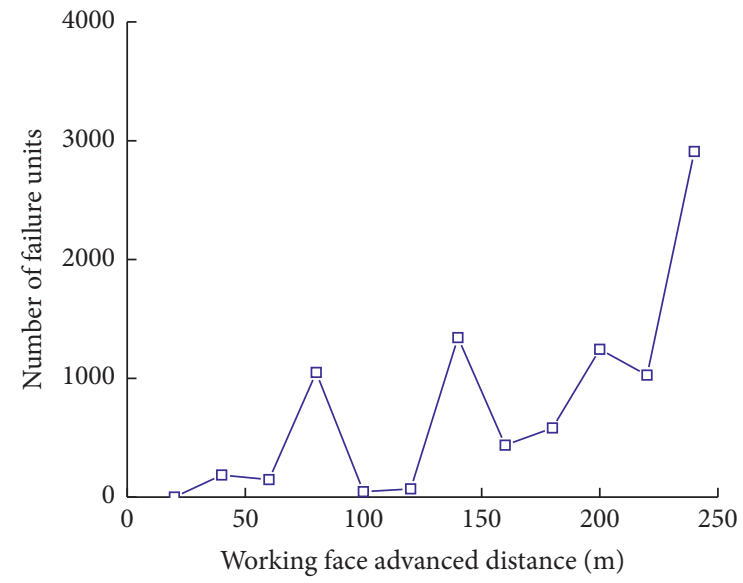

$\rightarrow$ tension_now

(a)

Figure 13: Continued. 


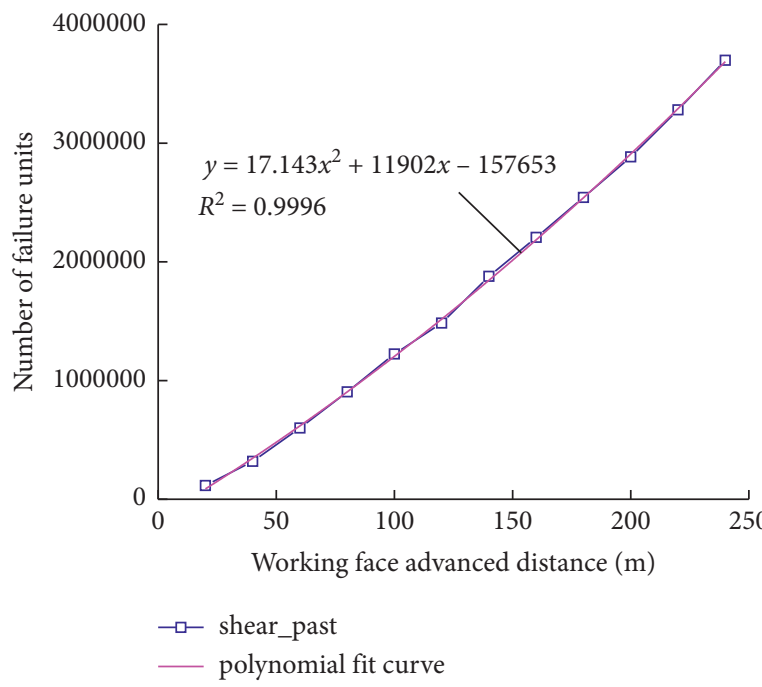

(c)

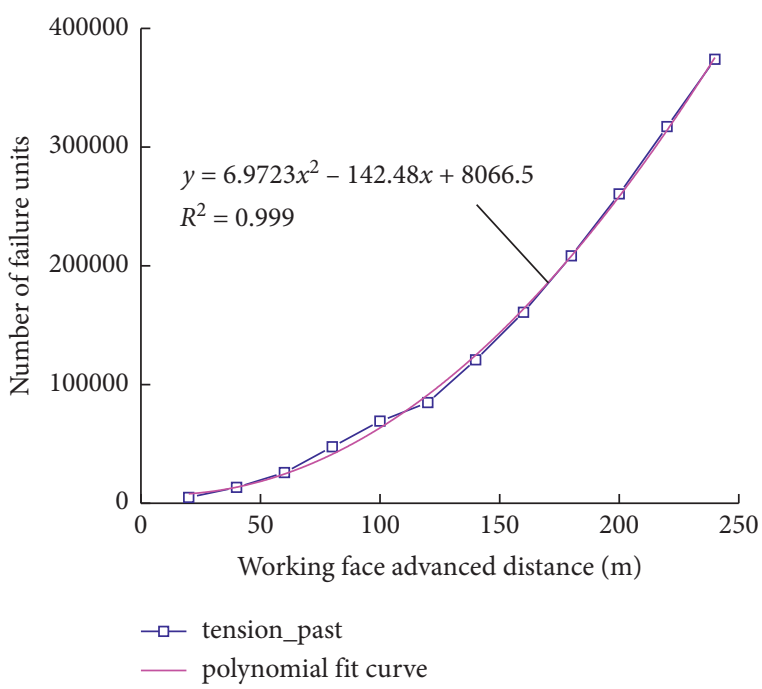

(d)

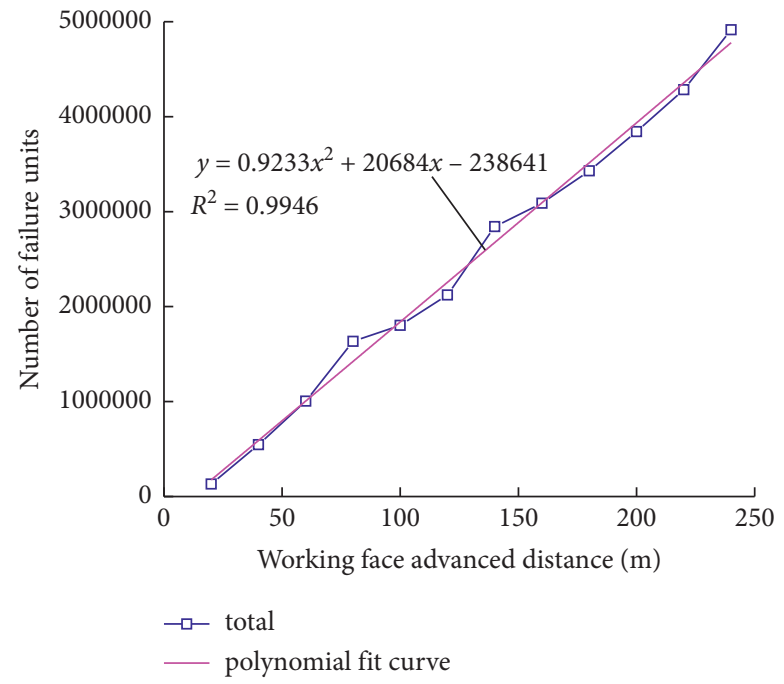

(e)

FIGURE 13: Failure units number of coal and rock mass in the mining process of the working face. (a) Shear_now; (b) tension_now; (c) shear_past; (d) tension_past; (e) total number of failure units.

It can be seen from Figure 13 that with the continuous development of the working face, the number of shear_now failure units increases gradually, reaching the maximum when the working face is recovered to $80 \mathrm{~m}$, and then, the fluctuation increases. The number of tensile_now failure units increases with the development of the working face and reaches the maximum when the working face advances to $240 \mathrm{~m}$. The number of shear_past failure units, tensile_past failure units, and the total failure units increased parabola with the progress of the working face.

\section{Conclusions}

(1) The in situ stress values of no. $2+3 \#$ coal seam are obtained by the stress relief method: the maximum principal stress is $24.79 \mathrm{MPa}$, the intermediate principal stress is $14.55 \mathrm{MPa}$, and the minimum principal stress is $9.87 \mathrm{MPa}$.
(2) The spatial-temporal evolution characteristics of coal and rock mass around the stope during coal mining are studied by the numerical simulation method, and the conclusions are as follows:

(1) As the working face goes on, the maximum value of the abutment stress formed in front, behind, and on both sides of the working face shifts to the corner, presenting a "hump-like" distribution. The stress concentration coefficient of front, back, and both sides of stope increases linearly with the increase of the mining size. Under the same mining size, the stress concentration coefficient in front of stope is the smallest, and the stress concentration coefficient on both sides is the largest. (2) With the continuous advance of the working face, the roof strata of the coal seam undergo the continuous dynamic subsidence process, and the roof subsidence increases continuously, showing a sharp bottom "bowl" shape, 
and the roof displacement of coal seam presents "O" shape evolution characteristics. (3) Obtain the threedimensional distribution nephogram of the plastic zone of coal and rock mass during the mining process of the working face, and the failure volume of the plastic zone gradually increased with the working face going on.

\section{Data Availability}

The data used to support the findings of this study have not been made available because research project is in progress.

\section{Disclosure}

The manuscript is presented in Research Square as preprint in Research Square according to the following link: "https:// www.researchsquare.com/article/rs-408320/v1."

\section{Conflicts of Interest}

The authors declare that they have no conflicts of interest.

\section{Acknowledgments}

This study was supported by the Research Fund of State and Local Joint Engineering Laboratory for Gas Drainage and Ground Control of Deep Mines Henan Polytechnic University) (SJF202004) and Huai'an Natural Science Research Program (HAB202154).

\section{References}

[1] H. W. Zhou, H. P. Xie, and J. P. Zuo, "Developments in researches on mechanical behaviors of rocks under the condition of high ground pressure in the depths," Advances in Mechanics, vol. 35, no. 1, pp. 91-99, 2005.

[2] Y. P. Cheng, X. L. Zhang, and L. Wang, "Controlling effect of ground stress on gas pressure and outburst disaster," Journal of Mining \& Safety Engineering, vol. 30, no. 3, pp. 408-414, 2013.

[3] J. P. Tang, S. L. Yang, Y. L. Wang, and J. Q. Lv, "Experiment of coal and gas outbursts under grand gas pressure in deep mines," Rock and Soil Mechanics, vol. 35, no. 10, pp. 2669-2774, 2014.

[4] C. X. Yu and X. F. Xian, "Analyses of finite element method for structural stress in coal series in a mine of southwest China," Journal of Guizhou Institute of Technology, vol. 19, no. 2, pp. 89-93, 1990.

[5] K. Tang and L. G. Komg, "The relationship of gas anomaly with structure stress and geo-temperature change of coalfield," Journal of Yunnan Geology, vol. 26, no. 3, pp. 322-327, 2007.

[6] F. X. Jiang, X. M. Zhang, S. H. Yang, X. Luo, Q. H. Ma, and H. J. Wang, "Discussion on overlying strata spatial structures of longwall in coal mine," Chinese Journal of Rock Mechanics and Engineering, vol. 25, no. 5, pp. 979-984, 2006.

[7] M. F. Cai, Principle and Technology of In-Situ Stress Measurement, Science Press, Beijing, China, 2000.

[8] Y. F. Liu, C. W. Luo, and Y. K. Liu, Situ Stress of Rock Mass and Engineering ConstructionHubei Science and Technology Press, Wuhan, China, 2000.
[9] D. M. Zhang, X. Bai, X. H. Qi, X. M. Zhang, and L. D. Yi, "Acoustic emission characteristics and in-situ stresses of bedding rock based on Kaiser effect," Chinese Journal of Rock Mechanics and Engineering, vol. 35, no. 1, pp. 87-97, 2016.

[10] Y. Yang, D. Zhang, S. Li, L. Yang, and L. Jin, "In-situ stress test and rockburst analysis in Micang Mountain tunnel," Energy Sources, Part A: Recovery, Utilization, and Environmental Effects, pp. 1-10, 2019.

[11] J. Sun, "Rock rheological mechanics and its advance in engineering applications," Chinese Journal of Rock Mechanics and Engineering, vol. 26, no. 6, pp. 1081-1106, 2007.

[12] J. Jiang, Q. Liu, and J. Xu, “Analytical investigation for stress measurement with the rheological stress recovery method in deep soft rock," International Journal of Mining Science and Technology, vol. 26, no. 6, pp. 1003-1009, 2016.

[13] Q. S. Liu, J. D. Jiang, C. Y. Zhang, and J. Xu, "Experimental investigation on the mechanical behavior of a new threedimensional pressure transducer," Arabian Journal for Science and Engineering, vol. 41, no. 12, pp. 1-12, 2016.

[14] Q. S. Liu, C. Y. Luo, Y. G. Zhu et al., "Research on orientation layout of pressure sensing units by rheological stress recovery method," Rock and Soil Mechanics, vol. 41, no. 1, pp. 336-341, 2020.

[15] L. M. Dou and H. He, "Study of OX-F-T spatial structure evolution of overlying strata in coal mines," Chinese Journal of Rock Mechanics and Engineering, vol. 31, no. 3, pp. 453-460, 2012.

[16] H. W. Zhang, H. Rong, J. Han, T. J. Cui, F. W. Yang, and J. Q. Sheng, "On the overburden failure height in the extrathick coal seams due to the "weak-weak" overburden structures in different mining stages," Journal of Safety and Environment, vol. 15, no. 6, pp. 45-50, 2015.

[17] H. S. Jia, N. J. Ma, and X. D. Zhao, "“Open-close” law of longitudinal transfixion cracks in shallow buried coal face with thin bedrock," Journal of China Coal Society, vol. 40, no. 12, pp. 2787-2793, 2015.

[18] J. H. Zhang, X. M. Song, and Y. P. Fu, "Study on strata behavior regularity and surrounding rock control of fullymechanized face in shallow coal seam with thin bedrock," Coal Technology, vol. 30, no. 11, pp. 75-76, 2011.

[19] G. Q. Lin, Behavior Features of Mining Pressure Appearance and the Performance of Supports in Thin Coal SeamChina University of mining and Technology, Beijing, China, 2013.

[20] Q. X. Wang and J. F. Ju, "Study on mine strata pressure behavior law of $450 \mathrm{~m}$ ultra long fully-mechanized coal mining face," Coal Science and Technology, vol. 42, no. 3, pp. 125-128, 2014.

[21] Y. F. Ren, Y. Ning, and Q. X. Qi, "Physical analogous simulation on the characteristics of overburden breakage at shallow longwall coalface," Journal of China Coal Society, vol. 38, no. 1, pp. 61-65, 2013.

[22] X. W. Yin, "Cutting block structure model of overburden with shallow buried coal seam and ultra-large mining height working face," Journal of China Coal Society, vol. 44, no. 7, pp. 1961-1970, 2019.

[23] C. A. Tang, Z. H. Xu, and X. H. Xu, "Application of RFPA2D system for rock fracture process analysis in the study of overburden strata movement law in stope," Journal of Liaoning University of Engineering and Technology (Natural Science Edition), vol. 18, no. 5, pp. 456-458, 1999.

[24] W. H. Yang, X. P. Lai, N. B. Wang, and X. F. Ai, "Disaster mechanism and prevention of strong rock pressure in steeply inclined horizontal sublevel fully-mechanized caving face," 
Journal of Xi'an University of Science and Technology, vol. 40, no. 2, pp. 221-228, 2020.

[25] X. Y. Zhang, Y. C. Xu, Y. B. Gao, G. M. Cao, and H. Duan, "Study of evolution laws of abutment pressure in front of a mining face when passing a collapse column," Journal of China University of Mining \& Technology, vol. 48, no. 2, pp. 278-286+321, 2019.

[26] Y. B. Gao, J. Yang, Q. Wang, Y. J. Wang, and M. C. He, "Mechanism of roof presplitting in a nonpillar mining method with entry automatically retained and its influence on the strata behaviors," Journal of China Coal Society, vol. 44, no. 11, pp. 3349-3359, 2019.

[27] H. W. Zhang, X. Z. Zhao, and J. Han, "Strata behavior characteristics of extra contiguous seams with repeated mining," Journal of Liaoning Technical University, vol. 37, no. 2, pp. 225-231, 2018.

[28] Y. S. Yang, D. M. Zhang, X. Bai, and H. Yang, "Research on correlation between abutment pressure and gas drainage flow of coal seam," Geotechnical \& Geological Engineering, vol. 36, no. 4, pp. 2087-2095, 2018.

[29] T. Wang, FLAC3D Numerical Simulation Method and Engineering Application, China Construction Industry Press, Beijing, China, 2015. 